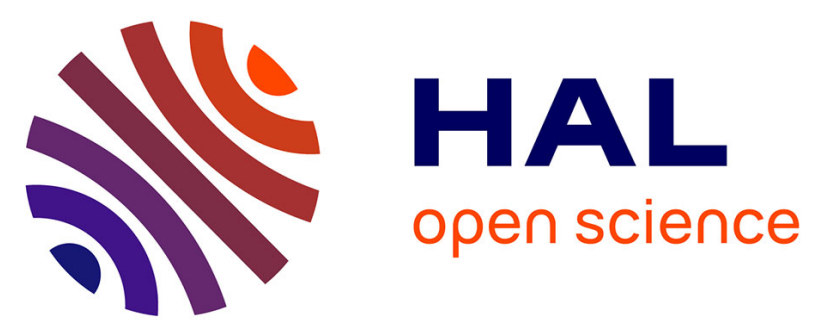

\title{
Enhanced properties for ultrasonic transduction, phase transitions and thermal depoling in 0.96(Bi0.5Na0.5) TiO3-0.04BaTiO3 submicrometre-structured ceramics
}

Lorena Pardo, Álvaro García, Klaus Brebøl, Elisa Mercadelli, Carmen Galassi

\section{- To cite this version:}

Lorena Pardo, Álvaro García, Klaus Brebøl, Elisa Mercadelli, Carmen Galassi. Enhanced properties for ultrasonic transduction, phase transitions and thermal depoling in 0.96(Bi0.5Na0.5)TiO30.04BaTiO3 submicrometre-structured ceramics. Journal of Physics D: Applied Physics, 2011, 44 (33), pp.335404. 10.1088/0022-3727/44/33/335404 . hal-00644270

\author{
HAL Id: hal-00644270 \\ https://hal.science/hal-00644270
}

Submitted on 24 Nov 2011

HAL is a multi-disciplinary open access archive for the deposit and dissemination of scientific research documents, whether they are published or not. The documents may come from teaching and research institutions in France or abroad, or from public or private research centers.
L'archive ouverte pluridisciplinaire HAL, est destinée au dépôt et à la diffusion de documents scientifiques de niveau recherche, publiés ou non, émanant des établissements d'enseignement et de recherche français ou étrangers, des laboratoires publics ou privés. 
Enhanced properties for ultrasonic transduction, phase transitions and thermal depoling in $0.96\left(\mathrm{Bi}_{0.5} \mathrm{Na}_{0.5}\right) \mathrm{TiO}_{3}-0.04 \mathrm{BaTiO}_{3}$ submicron structured ceramic

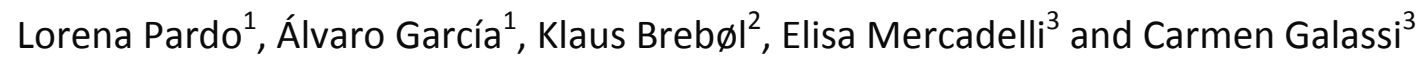 \\ ${ }^{1}$ Instituto de Ciencia de Materiales de Madrid. Consejo Superior de Investigaciones Científicas \\ (ICMM-CSIC). Cantoblanco. 28049- Madrid (Spain) \\ ${ }^{2}$ Limiel ApS. DK-4772 Langebæk (Denmark) \\ ${ }^{3}$ National Research Council of Italy, Institute of Science and Technology for Ceramics \\ (CNR-ISTEC). Via Granarolo, 64. I-48018 Faenza (Italy)
}

\title{
Abstract:
}

Submicron structured (grain size $\approx 500 \mathrm{~nm}$ ), dense $\left(\mathrm{Bi}_{0.5} \mathrm{Na}_{0.5}\right)_{0.96} \mathrm{Ba}_{0.04} \mathrm{TiO}_{3}$ ceramics were obtained from sol-gel autocombustion nanopowders by hot-pressing $\left(700-950^{\circ} \mathrm{C}\right)$ and subsequent recrystallization $\left(1000-1050^{\circ} \mathrm{C}\right)$. Electromechanical coefficients were obtained by analysis of the resonance spectra of thin disks using Alemany et al. software. The real part of the room temperature set of coefficients of the best performing materials $\left(\varepsilon^{\sigma}{ }_{33}=(416-16 i)\right.$, $d_{31}=\left(-22.68+0.55\right.$ i)pC $\left./ N^{-1}, k_{t}=44.5 \%, k_{p}=21.1 \%\right)$ can be compared with those of coarsegrained ceramics and $d_{33}\left(95 \mathrm{pC} . \mathrm{N}^{-1}\right)$ is higher. Shear related coefficients were obtained from thickness poled and length excited plates $\left(\varepsilon_{11}^{\sigma}=(402-89 i), d_{15}=(108.3-21.4 i) p C . N^{-1}\right.$ and $\mathrm{k}_{15}=39.2 \%$ ). At the depolarization temperature, $\mathrm{T}_{d}=153^{\circ} \mathrm{C}$, the dielectric loss, $\tan \delta(\mathrm{T})$, of poled samples shows a maximum and the planar resonance virtually vanishes. Shear resonance of thickness-poled plates and weak planar electromechanical resonance are observed above $T_{d}$. The relaxor behaviour extends up to the isotropization point, $\mathrm{T}_{\mathrm{i}}=238^{\circ} \mathrm{C}$. This can be understood as due to the coexistence of the room temperature ferroelectric phase in the stability range of the low temperature non-polar phase at zero field, between $T_{d}$ and $T_{i}$.

PACS: Dielectric materials, oxides, 77.84.Bw; piezoelectric materials, 77.84.-s; electromechanical resonance, 77.65.Fs; materials treatment effects on Microstructure, 81.40.-z; Structure of crystalline solids, 61.66.-f 


\section{Introduction}

Within the expanding area of the study of lead-free piezoelectrics, the (1- $x)$ $\left(\mathrm{Bi}_{0.5} \mathrm{Na}_{0.5}\right) \mathrm{TiO}_{3}-\mathrm{xBaTiO}_{3}(\mathrm{BNT}-\mathrm{BT})$ (BNBT100x) solid solution system [1] is being an area of high interest due to the peculiarities of its crystal structure [2]. Recently [3,4] it has been found that the phase diagram of unpoled ceramics differs from the one of poled ceramics, due to the electric-field induced phase transition observed for compositions near the MPB in BNT-based solid solution systems [5-8]. The nearly vertical Morphotropic Phase Boundary (MPB) composition, at $\mathrm{x} \approx 0.06$ for unpoled ceramics, can be shifted towards lower $\mathrm{x}$ values by the action of an electric field [2,7], which induces a ferroelectric phase. Due to these peculiarities, the electromechanical properties at the MPB are not as high as expected by similitude with the $\mathrm{Pb}(\mathrm{Zr}, \mathrm{Ti}) \mathrm{O}_{3}$ system. Another drawback of the MPB composition for some applications is that depoling temperature, at which most of the electromechanical activity vanishes by a mechanism still unclear, is low $\left(T_{d} \approx 100^{\circ} \mathrm{C}\right)[9]$.

When moving away from the MPB composition towards the $\left(\mathrm{Bi}_{0.5} \mathrm{Na}_{0.5}\right) \mathrm{TiO}_{3}$ side of the phase diagram, $T_{d}$ increases approaching that of $B N T\left(T_{d} \approx 187^{\circ} \mathrm{C}\right)[10]$ and the electromechanical coupling factors show higher anisotropy, i.e., higher ratio $k_{t} / k_{p}$ for the thickness and radial modes of thin disks, thickness poled [11]. In such a range of compositions, the reported electromechanical characterization in the ultrasonic range for $\mathrm{x}=0.04$ (BNBT4) ceramics is incomplete, lacking parameters related to shear modes of resonance. Shear coefficients have a key importance for 3D modeling of piezoceramics by numerical methods [12] due to the increasing number of their applications that are based on shear modes.

An issue in the preparation of BNBT ceramics is the loss of volatiles $(\mathrm{Bi}, \mathrm{Na})$ at the high sintering temperatures required $\left(T>1100^{\circ} \mathrm{C}\right)$, which leads to a.c. losses and d.c. conductivity that limits the poling and, consequently, the piezoelectric performance of the ceramics [10]. Sol-gel combustion synthesis [13] provides highly reactive nanopowder at moderate synthesis temperature $\left(500^{\circ} \mathrm{C}\right)$. Dense, submicron structured BNBT6 ceramics with good stoichiometry and properties that can be compared with those of coarse grain ceramics have been obtained by hot-pressing powder produced by sol-gel combustion and further recrystallization at $\mathrm{T} \leq 1050^{\circ} \mathrm{C}[14,15]$. Processing of ceramics from nanopowders allows nowadays to obtain fine grain ceramics. These are of interest for both the basic studies of size-effects in ferroelectrics and for their use as high frequency ultrasonic transducer materials, since they allow the miniaturization of the components. 
Submicron structured BNBT4 ceramics from nanopowder, prepared by hot-pressing and recrystallization, are studied in this work as candidates for ultrasonic transducer materials. Electromechanical characterization in the ultrasonic range is carried out from the resonances of thin disks, thickness poled and excited, and thickness-poled shear plates, length excited. Alemany et al. software $[16,17,18]$ is here used to analyze the impedance spectra at resonance and to calculate complex material coefficients. The thermal evolution of the dielectric permittivity and losses, as well as the one of the planar and shear modes of resonance, is also determined to evaluate the working range of the material.

\section{Experimental method}

(1-x) $\left(\mathrm{Bi}_{0.5} \mathrm{Na}_{0.5}\right) \mathrm{TiO}_{3}-\mathrm{xBaTiO}$ with $\mathrm{x}=0.04$ (BNBT4) nanometric powder was synthesized by a citrate, nitrate sol-gel auto-combustion method, as explained elsewhere [13]. In this process, the pure perovskite phase is directly obtained by heating the gel at $500{ }^{\circ} \mathrm{C}$. Pellets of the powder of $15 \mathrm{~mm}$ diameter and $1 \mathrm{~mm}$ thickness were obtained by uniaxial pressure forming followed by cold isostatic pressing at $200 \mathrm{MPa}$. A combination of hot-pressing at low temperature $\left(700-950^{\circ} \mathrm{C}\right.$ for $2 \mathrm{~h}$, at $20 \mathrm{MPa}$ in air, using heating and cooling rates of $\left.3^{\circ} \mathrm{C} \cdot \mathrm{min}^{-1}\right)$ and subsequent recrystallization at higher temperature $\left(1000\right.$ and $1050^{\circ} \mathrm{C}$ for $1-2 \mathrm{~h}$ in air) has been applied to sinter the green pellets. The BNBT4-1 to 3 ceramics studied were obtained with variable grain size and density to determine the microstructure leading to the optimum properties. Ceramics were characterized using X-ray diffraction (XRD, Siemens D500) and scanning electron microscopy (FEG-SEM, NOVA NANOSEM 230 with beam deceleration module) and their density was obtained by Archimedes method. Computer assisted quantitative microstructural characterization (MIP45 Digital Image System) was carried out by analysis and measurements of images of SEM and optical microscopy (OM, Leitz Laborlux 12 $\mathrm{MES} / \mathrm{ST})$. Both mean grain and pore size $(\langle\mathrm{G}\rangle$ and $\langle\mathrm{P}\rangle)$ of the ceramics were determined as the equivalent diameter to a circular shape $\left(D_{\text {eq }}=4(S / \pi)^{1 / 2}\right.$, where $S=$ grain or pore surface area) and from the analysis of the measured lognormal distributions of equivalent diameter [19] that also provides the corresponding standard deviations $\left(\sigma_{G}\right.$ and $\left.\sigma_{P}\right)$.

Sintered disks were ground to a thickness ( $t$ ) to diameter (D) ratio below $1 / 20$ (typically $\mathrm{t}=0.7 \mathrm{~mm}$ and $\mathrm{D}=15 \mathrm{~mm}$ ) and $\mathrm{Ag}$ electrodes were attached at their major faces for the electric poling and for the impedance measurements at the radial and thickness resonance modes. Rectangular plates of lateral dimensions $(\mathrm{L}, \mathrm{W})$ to thickness $(\mathrm{t})$ aspect ratio below $1 / 10$ (typically $\mathrm{t}=0.7 \mathrm{~mm}$ and $\mathrm{L}, \mathrm{W}=8-9 \mathrm{~mm}$ ) were also cut from the sintered ceramic disks, electroded and 
thickness poled. Poling electrodes were mechanically removed and a new pair of electrodes was applied on two of their perpendicular faces for the impedance measurements.

Owing to the reduced d.c. ceramic conductivity, it was possible to carry out poling of disks and plates in a silicone oil bath at $T_{p}=150-180^{\circ} \mathrm{C}$ up to fields of $45 \mathrm{kV} . \mathrm{cm}^{-1}$. Hot-poling took place for 30 minutes and the samples were cooled to room temperature with the field applied. The $d_{33}$ piezoelectric coefficient was measured in a Berlincourt-meter.

Piezoelectric coefficients of ferroelectric ceramics are currently calculated using standard methods $[20,21]$ from the measurements of complex impedance data at the electromechanical resonances. To overcome the well-known limitations of standard methods when dealing with material losses, alternative methods have been developed and will be used in this work. Fine-tuning of the thickness of the shear plates was carried out to minimize the coupling of the fundamental shear mode with other plate modes [12].

Complex impedance measurements at resonance were carried on using a HP4192A impedance analyzer controlled via a GPIB-PCIIA (National Instruments) interface board. Alemany et al. software $[16,17,18]$ was used here for the calculation of the complex piezoelectric, elastic and dielectric coefficients in each mode of resonance, as well as for the determination of the corresponding electromechanical coupling factors and frequency numbers. After the calculation of the complex parameters, the resonance spectrum is reconstructed as an accuracy test of the final set of calculated coefficients, quantified by the regression factor $\left(R^{2}\right)$ of such reconstruction.

Impedance measurements as a function of the temperature were carried out at various frequencies in the range between $1 \mathrm{kHz}$ and $1 \mathrm{MHz}$ with a HP4194A analyzer. The heating and cooling rates were $2^{\circ} \mathrm{C} / \mathrm{min}$. From these experimental data and the geometric factor thickness/area, the relative dielectric permittivity $\varepsilon^{*}=\varepsilon^{\prime}-i \varepsilon^{\prime \prime}$, and dielectric losses, $\tan \delta=\varepsilon^{\prime \prime} / \varepsilon^{\prime}$ were obtained. This experimental set-up was also used for determination of the resonance spectra as a function of temperature.

\section{Experimental results}

Fig.1 shows the XRD patterns of the unpoled ceramics. All of them have a single phase distorted perovskite type structure to the resolution of the technique. Peaks are indexed for a R3c rhombohedral symmetry, BNT-like, in hexagonal description (JCPDS file \#70-9850). However, due to proximity to the MPB, signs of mixed phases [7] are observed in the unpoled samples. Fig. 2 shows, as an example, two selected $2 \theta$ ranges in the XRD patterns of the BNBT4- 
1 ceramic, around $40^{\circ} 2 \theta$ the doublet (006),(202) and around $46.5^{\circ} 2 \theta$ the (024) peak, before and after poling. A clear field-induced phase transition with change of crystal symmetry is not observed in any of the ceramics, but the (024) peak becomes sharper, i.e., the rhombohedral character is enhanced. The texture change due to domain orientation during poling is observed by the change in relative intensity in the (006),(202) doublet. These changes are in agreement with recently reported results [7].

The results of the quantitative characterization of the microstructure of the samples (relative density and number of objects measured in the micrographs, average values and standard deviation of the distributions) are reported in Table I. Fig. 3 shows the SEM images from which the values of average grain size, shown in Table I, were calculated. Fig. 4 shows an example of the intermediate steps in the quantitative microstructural analysis and size distributions of grain (from SEM images) and pore (from OM images).

Fig. 5 shows the resonance spectra (resistance and conductance peaks, real parts of the complex impedance, $\mathrm{Z}^{*}=\mathrm{R}+\mathrm{iX}$, and admittance, $\mathrm{Y}^{*}=\mathrm{G}+\mathrm{iB}$, respectively) of the radial or planar (Fig. 5(a)) and thickness (Fig. 5(b)) modes of, thickness poled and excited, thin disk and the shear mode of, thickness-poled and length excited, shear plate (Fig. 5(c)) of BNBT4-2 ceramic. Both the experimental (symbols) and reconstructed spectrum (lines) are shown for each resonance.

Table II summarizes the relative density, range of grain size, $d_{33}$ from Berlincourt-meter and the piezoelectric $\left(h_{33}, e_{33}, d_{31}, g_{31}\right)$, elastic $\left(c_{33}{ }^{D}, c_{11}{ }^{D}, s_{11}{ }^{E}, s_{12}{ }^{E}, s_{66}{ }^{E}\right)$ and dielectric $\left(\varepsilon^{S}{ }_{33}, \varepsilon^{\sigma}{ }_{33}\right)$ linear coefficients, including all losses, which are calculated from the measured radial and thickness resonances of thin disks. The Poisson ratio, electromechanical coupling factors $\left(k_{p}, k_{t}\right)$ and frequency numbers $\left(N_{p}, N_{t}\right)$ are shown in Table II. Similarly, Table III summarizes the material data $\left(\mathrm{e}_{15}, \mathrm{~d}_{15}, \mathrm{~h}_{15}, \mathrm{~g}_{15}, \mathrm{c}_{11}{ }^{\mathrm{D}}, \mathrm{S}_{55}{ }^{\mathrm{E}}, \varepsilon^{\mathrm{S}}{ }_{11}, \varepsilon^{\sigma}{ }_{11}, \mathrm{k}_{15}, \mathrm{~N}_{15}\right)$ obtained from the shear resonance of thickness poled plates. Tables II and III show also published data for dense BNBT6 and BNBT4 ceramics obtained by different processing routes [11, 22, 23] and for BNT ceramics [10].

Fig. 6 shows the real part of the relative dielectric permittivity and the dielectric loss as a function of the temperature for the BNBT4-1 sample. Results are shown for the unpoled ceramic, both measuring on heating and cooling, as well as for the poled ceramic measured on heating and for the thermally depoled ceramic measured on cooling. The observed differences can be discussed in terms of the structural changes induced by the poling field.

Fig. 7 shows for BNBT4-2 the evolution with the temperature of conductance peak, characteristic frequencies and electromechanical coupling factors of the planar resonance of a thin disk and the shear resonance of a thickness-poled plate. 


\section{Discussion}

\section{Electromechanical properties at room temperature}

As shown in Tables I to III, the properties of dense and submicron structured BNBT4-2 and 3 ceramics are in good agreement with previously reported values for coarser grained BNBT4 ceramics prepared at higher temperatures [11]. BNBT4-1 ceramic shows similar grain size, but lower relative density (Table I) and, therefore, higher porosity, than BNBT4-2 and 3. This results in higher compliance and mechanical and dielectric losses, as well as lower coupling coefficients (Table II). The optimum set of properties is found for the combination of submicron grain size and low porosity of BNBT4-2 (Tables II and III). This can be understood as a consequence of a good stoichiometry, arising from the low processing temperatures, and homogeneous microstructure (Figs. 1 and 3 ) that reduces conductivity and losses and allows efficient poling at relatively high temperature.

BNBT4-2 and 3 ceramics show values of the properties in between those of BNBT6 and BNT composition. The dielectric permittivity $\left(\varepsilon^{\sigma}{ }_{33}\right)$ is lower than in BNBT6 and higher than in BNT; the thickness coupling factor and electromechanical anisotropy are higher $\left(k_{t} / k_{p}=2.2\right)$ than in BNBT6 $\left(k_{t} / k_{p}=1.5\right)$, approaching the value of BNT, whereas $d_{33}$ piezoelectric coefficient is higher than in BNT, approaching the value of BNT6 (Table II).

The comparison of the data obtained in submicron structured ceramics from nanopowder evidences that the dielectric losses, as well as the piezoelectric $e_{33}, d_{31}, g_{31}$ are lower for the BNBT4 composition than for the BNBT6. Also, when comparing real values of all elastic $\mathrm{s}_{\mathrm{ij}}$ coefficients and the frequency numbers it is observed that BNBT4 ceramic is similar to BNBT6 from the mechanical point of view, but the losses are also lower.

Table III shows the characterization for the shear mode in which, again, we found that values of BNBT4 properties are intermediate from those of BNBT6 and BNT. The free permittivity $\left(\varepsilon^{\sigma}{ }_{11}\right)$, the shear coupling factor and the $d_{15}$ piezoelectric coefficient of BNBT4 are higher than those of BNT, approaching the values of BNBT6.

Besides these interesting properties and just as an example among the many studies on doping BNBT ceramics to enhance electromechanical performance, $\mathrm{CaO} / \mathrm{MnO}$ co-doping [24] has shown efficiency in increasing $d_{33}, k_{p}$ and $k_{t}$. At the same time the depolarization temperature is almost unchanged, the sinterability increases and the grain size of the ceramics is reduced. Therefore, routes for further improvement of the properties of pure BNBT4 ceramics for ultrasonic transduction purpose by doping are avaliable. 


\section{Temperature evolution of the permittivity and electromechanical properties}

The curves of the real part of the dielectric permittivity as a function of temperature have a maximum at $\mathrm{T}_{\mathrm{m}}=275^{\circ} \mathrm{C}$ and are dispersive up to $\sim 238^{\circ} \mathrm{C}$ on heating and $\sim 225^{\circ} \mathrm{C}$ on cooling (Fig. 6). This upper limit temperature for the dispersive region is often ascribed in BNTbased compositions [1] to $T_{R-T}$, the transition temperature from the room temperature ferroelectric (rhombohedral) $(F E(R))$ phase to the antiferroelectric (tetragonal) $(A F E(T)$ ) phase by similitude with BNT. However, it resembles more to the isotropization point $\left(T_{i}\right)$ of the optical properties of BNT $\left(T_{R-T}<T_{i}<T_{m}\right)$, which is associated to a local maximum in the first derivative of the real part of the dielectric permittivity vs. temperature curve $d \varepsilon^{\prime} / d T$ [25]. Early interpretation of $T_{i}$ on cooling involved the percolation phenomena of the AFE regions that begin to form at $T_{m}$ within the ferroelastic twins formed in the paraelectric-ferroelastic (PEFelas) phase, stable above $T_{m}$. This ferroelastic twins originates on cooling from the paraelectric-paraelastic (PE-Pelast) cubic phase, stable above $540^{\circ} \mathrm{C}$ for pure BNT. The percolation of the AFE regions creates long-range AFE order in the crystal. On heating, the complete separation of AFE regions at $T_{i}$ can only take place when a critical density of PE-Felast interlayer takes place. This requires a higher temperature, thus the observed thermal hysteresis of $T_{i}$. It is clear that the temperature of formation on cooling and destruction on heating of the long range ordered AFE phase will correspond to the most unstable state of the crystal and thus to a $\mathrm{d} \varepsilon^{\prime} / \mathrm{dT}$ local maximum. The AFE character of the BNT-based compositions is under discussion. The term Low Temperature Non-Polar at Zero Field phase (LTNPZF), which would account with the pinched hysteresis loops characteristic of the phase taking place above $T_{R-T}$, seems more appropriated [26]. The depolarization temperature for BNBT4 is the temperature at which the ferroelectric long-range order and macroscopic ferroelectric properties disappear, $T_{\mathrm{R}-\mathrm{T}}$ or, more properly, $\mathrm{T}_{\mathrm{FE}-\mathrm{LTNPZF}}$. A recent work [3] has coined the term antiferroelectric-relaxor, which will account with the dielectric dispersion found in the range of stability of this phase, between $T_{F E-L T N P Z F}$ and $T_{i}$.

On heating of the poled sample, $T_{d}=T_{F E-L T N P Z F}$ is revealed by the sharp jump in the real part of the permittivity and the maxima of the losses at $\sim 153^{\circ} \mathrm{C}$ for BNBT4 (Fig. 6), in good agreement with previous results from depolarization current [11]. Whereas there are not differences in the curves of the real part of the permittivity versus temperature measured on cooling, the difference between measurements on heating of the samples before and after poling is clear, being $\varepsilon_{33}^{\sigma}$ (poled) $>\varepsilon^{\prime}$ (unpoled) in the interval between $T_{d}=T_{F E-L T N P F}$ and $T_{i}$ (Fig. 6). 
As shown in Fig. 7, for $T_{d} \approx 150^{\circ} \mathrm{C}$ we found $\mathrm{f}_{s} \approx \mathrm{f}_{\mathrm{p}}$ in the resonance spectrum of the planar mode as a function of the temperature. The electromechanical coupling factor calculated using standard methods vanishes at $T_{d}$. However, a weak resonance spectrum was observed up to higher temperatures and it is possible to obtain $\mathrm{k}_{\mathrm{p}} \neq 0$ up to $\mathrm{T} \approx 230^{\circ} \mathrm{C}$ using Alemany et al. software (Fig. 7). This residual macroscopic piezoelectricity indicates that, although the longrange $\mathrm{FE}$ order disappear at $\mathrm{T}_{\mathrm{d}}$, it may exist a medium-range order [27] by coexistence of $\mathrm{FE}$ clusters in the LTNPZF phase above $T_{d}$, also reflected in the differences of the permittivity before and after poling between $\mathrm{T}_{\mathrm{FE}-\mathrm{LTNPF}}$ and $\mathrm{T}_{\mathrm{i}}$. Such a medium-range order progressively disappears as the temperature increases towards $T_{i}$. For BNT [28] and BNT-BKT-BT [5] ceramics a weak piezoelectric activity above $\mathrm{T}_{\mathrm{FE}-\mathrm{LTNPZF}}=200^{\circ} \mathrm{C}$ and $177^{\circ} \mathrm{C}$, respectively, was also previously reported.

When the shear resonance is studied in a similar manner, the observed depolarization temperature, as defined by the point in which $\mathrm{f}_{\mathrm{s}} \approx \mathrm{f}_{\mathrm{p}}$, is found at a higher temperature $\left(T_{d}{ }^{S H} \approx\right.$ $175^{\circ} \mathrm{C}$ ) (Fig. 7). The electromechanical anisotropy here observed reveals the complexity of the depolarization process of these samples. This anisotropy could arise from a texture developed during hot-pressing or by a mechanism of progressive dissapearance of the FE clusters that reduces first the polarization extension mechanisms and, at higher temperature, the polarization rotation mechanisms associated to the shear mode. Dielectric anisotropy has been reported for BNT ceramics [10]. The full explanation of the mechanism underlying these effects exceeds the purpose of this work and demands additional structural information. It is clear, however, from the results in Fig. 7 that the working range of BNBT4 ceramics extends to higher temperatures than the currently reported $T_{d}$ when the applications are based on shear resonances.

\section{Conclusions}

Submicron structured, dense $\left(\mathrm{Bi}_{0.5} \mathrm{Na}_{0.5}\right)_{1-\mathrm{x}} \mathrm{Ba}_{\mathrm{x}} \mathrm{TiO}_{3}$ ceramics with $\mathrm{x}=0.04$ were obtained and studied as candidates for lead-free ultrasonic transducer materials. For BNBT4 ceramics, the free permittivity $\left(\varepsilon^{\sigma}{ }_{33}, \varepsilon^{\sigma}{ }_{11}\right)$, the $k_{t}$ and $k_{15}$ coupling factors and electromechanical anisotropy $\left(k_{t} / k_{p}\right)$ are higher than for BNBT6. The $d_{33}, d_{31}$ and $d_{15}$ piezoelectric coefficient are higher in BNBT4 than in BNT, approaching the values for BNT6. The comparison of ceramics from sol-gel auto-combustion nanopowder also evidences that BNBT4 ceramics have lower dielectric, mechanical and piezoelectric losses than BNBT6 ceramics. BNBT4 has higher depolarization temperature than BNBT6, which is $\mathrm{T}_{\mathrm{d}} \approx 150^{\circ} \mathrm{C}$ when determined from dielectric 
loss measurements in poled samples and thermal evolution of the radial mode spectrum.

Finally, an electromechanical anisotropy was observed during the thermal depolarization. The depolarization temperature from the evolution of the shear mode spectrum is found to be $\mathrm{T}_{\mathrm{d}}^{\mathrm{SH}} \approx 175^{\circ} \mathrm{C}$.

\section{Acknowledgements}

This work was funded by Spanish CSIC project \#201060E069 and supported by the European Network of Excellence (NoE-MIND CE FP6 515757-2), that established the European Institute of Piezoelectric Materials and Devices (Piezoinstitute). Authors wish to thank Mr. José Luis Millán (FINNOVA 2010 grantee) for his technical assistance in the quantitative microstructural characterization. 


\section{References}

[1] T.Takenaka, H. Nagata and Y. Hiruma. "Phase Transition Temperatures and Piezoelectric Properties of $\left(\mathrm{Bi}_{1 / 2} \mathrm{Na}_{1 / 2}\right) \mathrm{TiO}_{3}$ - and $\left(\mathrm{Bi}_{1 / 2} \mathrm{~K}_{1 / 2}\right) \mathrm{TiO}_{3}$-Based Bismuth Perovskite Lead-Free Ferroelectric Ceramics". IEEE Trans. Ultrasonics, Ferroelectrics and Frequency Control 56(8), 1595-1612(2009).

[2] B.W. van Eerd, D. Damjanovic, N. Klein, N. Setter and J. Trodahl. "Structural complexity of $\left(\mathrm{Na}_{0.5} \mathrm{Bi}_{0.5}\right) \mathrm{TiO}_{3}-\mathrm{BaTiO}_{3}$ as revealed by Raman Spectroscopy". Physical Review B $\underline{82}, 104112$ (2010).

[3] C. Ma, X. Tan, E. Dul'kin and M. Roth. "Domain structure-dielectric property relationship in lead-free (1-x) $\left(\mathrm{Bi}_{1 / 2} \mathrm{Na}_{1 / 2}\right) \mathrm{TiO}_{3}-\mathrm{xBaTiO}_{3}$ ceramics". J. Appl. Phys. 108, 104105 (2010).

[4] W.Jo, J.E. Daniels, J.L.Jones, X.Tan, P. Thomas, D. Damjanovic and J. Rodel. "Evolving morphotropic phase boundary in lead-free $\left(\mathrm{Bi}_{1 / 2} \mathrm{Na}_{1 / 2}\right) \mathrm{TiO}_{3}-\mathrm{BaTiO}_{3}$ piezoceramics". J. Appl. Phys. 109 , 014110 (2011).

[5] Y. Hiruma, H. Nagata and T. Takenaka. "Phase Transition Temperatures and Piezoelectric Properties of $\left(\mathrm{Bi}_{1 / 2} \mathrm{Na}_{1 / 2}\right) \mathrm{TiO}_{3}-\left(\mathrm{Bi}_{1 / 2} \mathrm{~K}_{1 / 2}\right) \mathrm{TiO}_{3}-\mathrm{Ba}_{\times} \mathrm{TiO}_{3}$ LeadFree Piezoelectric Ceramics". Jap. J. Appl. Phys. 45(9B), 7409-7412 (2006).

[6] J.E. Daniels, W. Jo, J. Rodel and J.L. Jones."Electric-field-induced phase transformation at a lead-free morphotropic phase boundary: Case study in $93 \%\left(\mathrm{Bi}_{0.5} \mathrm{Na}_{0.5}\right) \mathrm{TiO}_{3}-7 \% \mathrm{BaTiO}_{3}$ piezoelectric ceramic". Appl. Phys. Lett. 95 , 032904-1-3 (2009).

[7] G. Pitch, J. Topfer and E. Hennig. "Structural properties of $\left(\mathrm{Bi}_{0.5} \mathrm{Na}_{0.5}\right)_{1-x} \mathrm{Ba}_{x} \mathrm{TiO}_{3}$ lead-free piezoelectric ceramics". J. Eur. Ceram. Soc. 30, 3445-3453 (2010).

[8] A. J. Royles, A. J. Bell, A. P. Jephcoat, A.K. Kleppe, S.J. Milne and T.P. Comyn. "Electric-fieldinduced phase switching in the lead-free piezoelectric potassium sodium bismuth titanate". Appl. Phys. Lett. 97, 132909 (2010).

[9] D.Q. Xiao, L. Wu, J.G. Zhu. "Temperature stability of Lead-free Piezoelectric Ceramics of Perovskite $\mathrm{Bi}_{0.5} \mathrm{Na}_{0.5} \mathrm{TiO}_{3}$ and $\mathrm{K}_{0.5} \mathrm{Na}_{0.5} \mathrm{NbO}_{3}$ Families". 18th IEEE International Symposium on the Applications of Ferroelectrics (ISAF2009) 3-27 Aug. 2009. Xiam, China.

DOI:10.1109/ISAF.2009.5307596

[10] Y. Hiruma, H. Nagata and T. Takenaka. "Thermal depoling process and piezoelectric properties of bismuth sodium titanate ceramics". J. Appl. Phys. 105 , 084112-1-8 (2009). [11] B.J. Chu, D.R. Chen, G.R. Li and Q.R. Yin. "Electrical properties of $\mathrm{Na}_{1 / 2} \mathrm{Bi}_{1 / 2} \mathrm{TiO}_{3}-\mathrm{BaTiO}_{3}$ ceramics". J. Eur. Ceram. Soc. 22 , 2115-2121 (2002).

[12] L. Pardo, A. Garcia, F. Montero De Espinosa and K. Brebøl. "Shear Resonance Mode Decoupling to Determine the Characteristic Matrix of Piezoceramics for 3-D Modelling". IEEE Trans. Ultrasonics, Ferroelectrics and Frequency Control 58 (3), 646-657 (2011).

[13] E. Mercadelli, C. Galassi, A.L. Costa, S.Albonetti and A. Sanson. "Sol-gel combustion synthesis of BNBT powders". J. Sol-Gel Sci. Tech. $\underline{46}(1), 39-45$ (2008).

[14] A. Moure, A. Castro and L. Pardo. "Improvement by Recrystallization of Aurivillius-type Piezoceramics from Mechanochemically Activated Precursors". Acta Mater., 52 , 945 (2004). [15] L. Pardo, E. Mercadelli, K. Brebøl, A. García and C. Galassi. "Piezoelectric properties of leadfree submicron structured $\left(\mathrm{Bi}_{0.5} \mathrm{Na}_{0.5}\right)_{0.94} \mathrm{Ba}_{0.06} \mathrm{TiO}_{3}$ ceramics". Smart Materials and Structures $\underline{19}(11), 115007$ (2010).

[16] C. Alemany , L. Pardo, B. Jiménez, F. Carmona, J. Mendiola and A.M.González. "Automatic iterative evaluation of complex material constants in piezoelectric ceramics". J. Phys. D: Appl.

Phys. $27,148-155$ (1994).

[17] C. Alemany, A. M. Gónzalez, L. Pardo, B. Jiménez, F. Carmona, J. Mendiola "Automatic determination of complex constants of piezoelectric lossy materials in the radial mode" J. Phys. D: Appl. Phys. 28 , 945-956 (1995). 
[18] L. Pardo, M. Algueró and K. Brebøl. "A Non-Standard Shear Sample for the Matrix Characterization of Piezoceramics and itsValidation Study by Finite Element analysis". J. Phys. D: Appl. Phys. $\underline{40}$, 2162-2169 (2007).

[19] J. Ricote and L. Pardo. "Microstructure-properties relationships in Sm-modified lead titanate piezoceramics. Part I: Quantitative study of the microstructure". Acta Mater. 44, 11551167 (1996).

[20] "IEEE Standard on piezoelectricity". ANSI/IEEE Std. 176-1987.

[21] "Piezoelectric properties of ceramic materials and components. Part 2: methods of measurement - Low power". European Standard CENELEC, EN 50324-2 (2002).

[22] L. Pardo, E. Mercadelli, A.García, K. Brebøl and C. Galassi. "Field-induced phase transition and relaxor character in submicron structured lead-free $\left(\mathrm{Bi}_{0.5} \mathrm{Na}_{0.5}\right)_{0.94} \mathrm{Ba}_{0.06} \mathrm{TiO}_{3}$ piezoceramics at the morphotropic phase boundary". IEEE Trans. Ultrasonics, Ferroelectrics and Frequency Control (in press, 2011).

[23] T. Takenaka, A. Huzumi, T. Hata and K. Sakata. "Mechanical properties of $\left(\mathrm{Bi}_{1 / 2} \mathrm{Na}_{1 / 2}\right) \mathrm{TiO}_{3}$ based piezoelectric ceramics". Silicates Industriels $\underline{7}(8), 136-142$ (1993).

[24] M.S. Yoon,Y.G. Lee and S.C.Ur. "Effects of co-doped $\mathrm{CaO} / \mathrm{MnO}$ on the piezoelectric /dielectric properties and phase transition of lead-Free $\left(\mathrm{Bi}_{0.5} \mathrm{Na}_{0.5}\right)_{0.94} \mathrm{Ba}_{0.06} \mathrm{TiO}_{3}$ piezoelectric ceramics". J. Electroceram. 23 564-571 (2009).

[25] V.A. Isupov. "Ferroelectric $\mathrm{Na}_{0.5} \mathrm{Bi}_{0.5} \mathrm{TiO}_{3}$ and $\mathrm{K}_{0.5} \mathrm{Bi}_{0.5} \mathrm{TiO}_{3}$ perovskites and their solid solutions". Ferroelectrics 315 123-147 (2005).

[26] S. B. Vakhrushev, V.A. Isupov, B.E. Kvyatkovsky, N.M. Okuneva, I.P. Pronin, G.A. Smolensky and P.P. Syrnikov. "Phase transitions and soft modes in sodium bismuth titanate". Ferroelectrics $\underline{63}, 153-160$ (1985).

[27] M. Shen, J. Han and W. Cao. "Electric-field-induced dielectric anomalies in c-oriented $0.955 \mathrm{~Pb}\left(\mathrm{Zn}_{1 / 3} \mathrm{Nb}_{2 / 3}\right) \mathrm{O}_{3}-0.045 \mathrm{PbTiO}_{3}$ single crystals". Appl. Phys. Lett. $\underline{83}$ (4), 731 (2003).

[28] K. Roleder, I. Franke, A.M. Glazer, P.A. Thomas, S. Miga and J. Suchanicz. "The piezoelectric effect in $\mathrm{NaBiTiO}_{3}$ ceramics". J. Phys.: Condens. Matter. 14 (2002) 5399-5406. 


\section{Figure captions}

Fig. 1. XRD pattern of BNBT4 ceramics.

Fig. 2. Selected peaks of the XRD pattern of the BNBT4-1 $\left(\mathrm{HP} 700^{\circ} \mathrm{C}-2 \mathrm{~h}+1050^{\circ} \mathrm{C}-1 \mathrm{~h}\right)$ ceramic before and after poling : (a) around $40^{\circ} 2 \theta$ the doublet (006),(202) and (b) around $46.5^{\circ} 2 \theta$ the (024) peak.

Fig. 3. SEM micrographs of ceramic surfaces polished and quenched from $800^{\circ} \mathrm{C}$ to room temperature: (a) BNBT4-1 (HP700 $\left.{ }^{\circ} \mathrm{C}-2 \mathrm{~h}+1050^{\circ} \mathrm{C}-1 \mathrm{~h}\right)$ ), (b) BNBT4-2 (HP800 ${ }^{\circ} \mathrm{C}-2 \mathrm{~h}+1050^{\circ} \mathrm{C}-1 \mathrm{~h}$ ) and (c) BNBT4-3 (HP950 $\left.{ }^{\circ} \mathrm{C}-2 \mathrm{~h}+1000^{\circ} \mathrm{C}-2 \mathrm{~h}\right)$.

Fig. 4. Steps of the process of quantitative microstructural characterization of the BNBT4-2 (HP800 ${ }^{\circ} \mathrm{C}-2 \mathrm{~h}+1050^{\circ} \mathrm{C}-1 \mathrm{~h}$ ) ceramics: original grey level images from microscopy, objects identified in the corresponding digital images for the measurement of their areas and lognormal distributions of grain (Figs. (a)-(c)) and pore (Figs. (d)-(f)) equivalent diameters.

Fig. 5. Resonance spectra of BNBT4-2 ceramic thin disk (Figs. (a) and (b)) and shear plate (Fig. (c)). Experimental (symbols) and reconstructed (lines) spectra after calculation of coefficients by Alemany et al. software are shown for all resonances.

Fig. 6. BNBT4-1 ceramic: dielectric permittivity, real part and losses, of unpoled samples on heating and cooling (Figs. (a) and (b)) and after poling (Figs. (c) and (d)) on heating and on cooling of the thermally depoled sample. Arrows indicate the increasing measurement frequency $(1,2,5,10,50,100,200,500$ and $1000 \mathrm{kHz})$.

Fig. 7. Thermal dependence of the conductance peaks (Figs. (a) and (b)) and of the characteristic frequencies and electromechanical coupling factors for the radial mode of a thickness poled and excited thin disk (Fig. (c)) and the shear mode of a thickness-poled and length excited shear plate (Fig. (d)) of BNBT4-2.

\section{Table captions}

Table I. Results of the quantitative characterization of the ceramic microstructure: density and characteristics of the lognormal distributions of equivalent diameters of grains (from SEM images) and pores (from OM images).

Table II. Piezoelectric, elastic and dielectric parameters, electromechanical coupling factors and frequency numbers, obtained from measurement of the planar $(P)$ and thickness $(T)$ resonances of thin disks of BNBT4 ceramics, poled and excited in thickness. Data from the literature are also shown for comparison.

Table III. Piezoelectric, elastic and dielectric parameters, as well as electromechanical coupling factors and frequency numbers, obtained from the shear resonance of plates of BNBT4 ceramics, thickness poled and length excited. Data from the literature are also shown for comparison. 


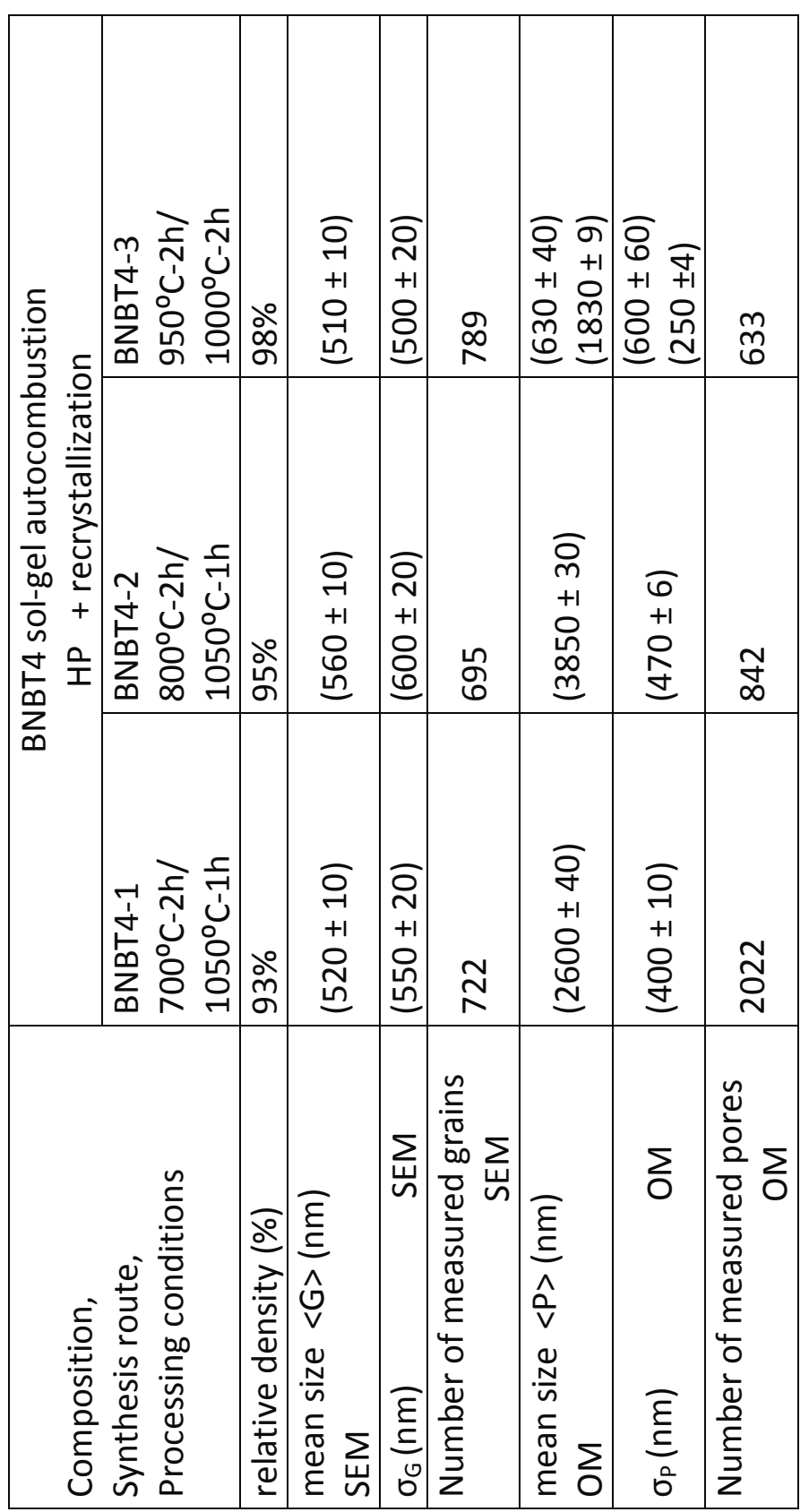




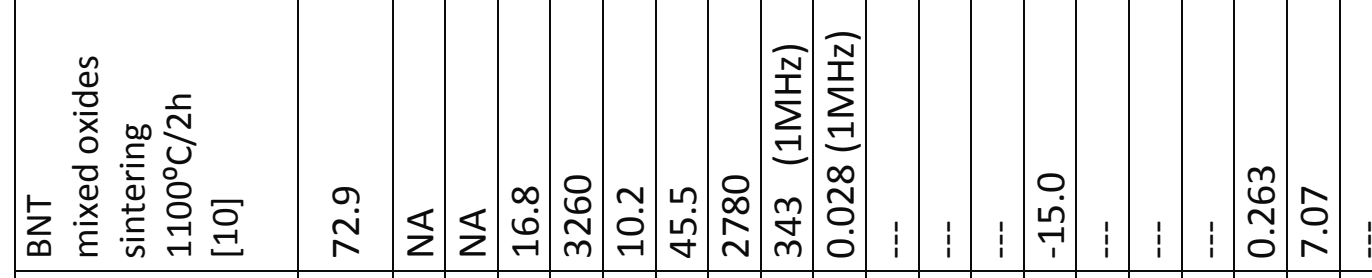

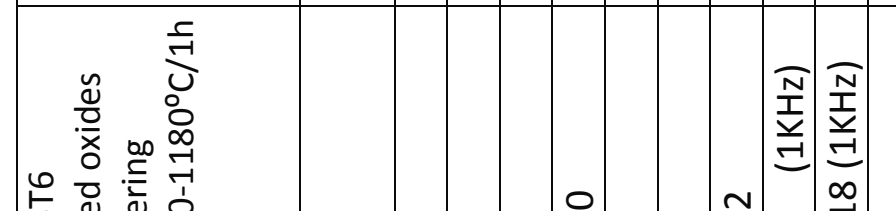

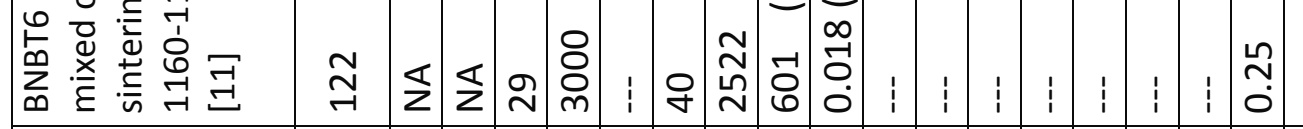

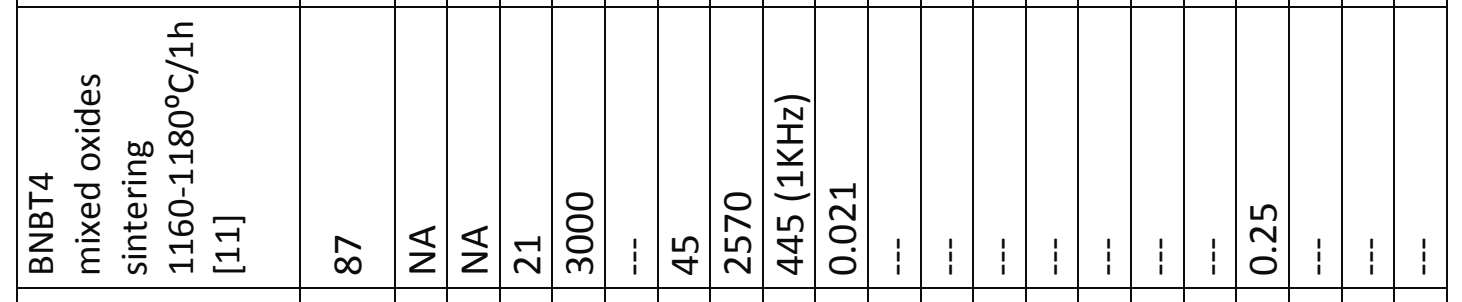

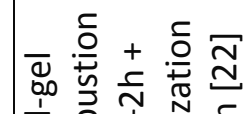

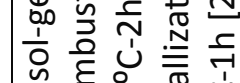

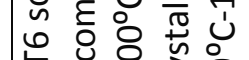

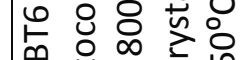

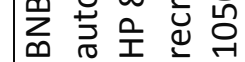

go

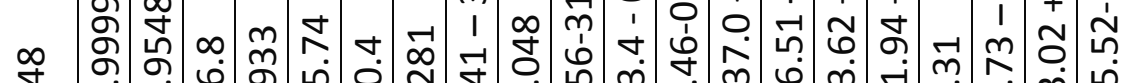

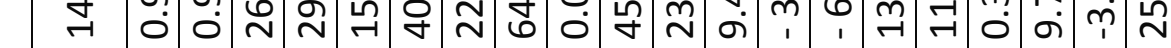

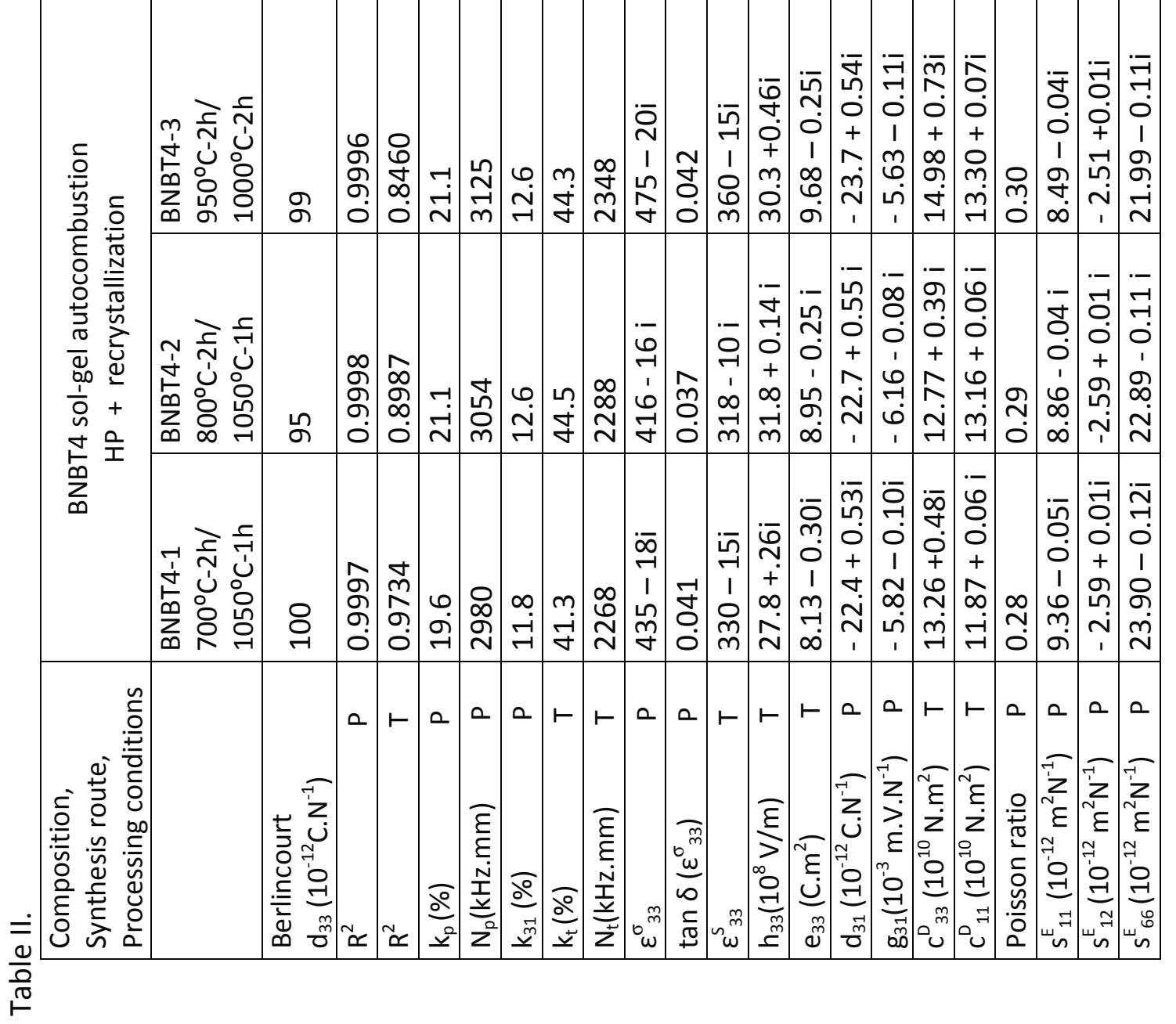




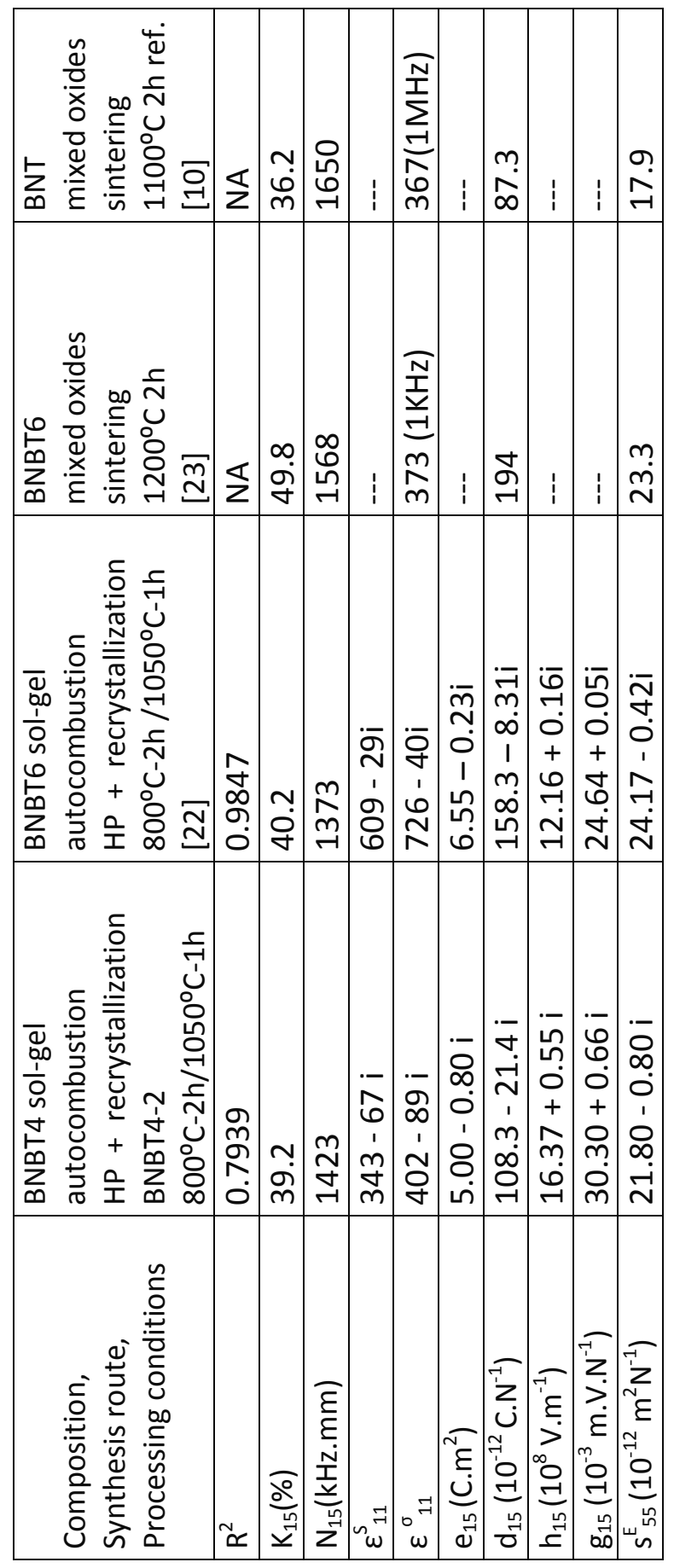




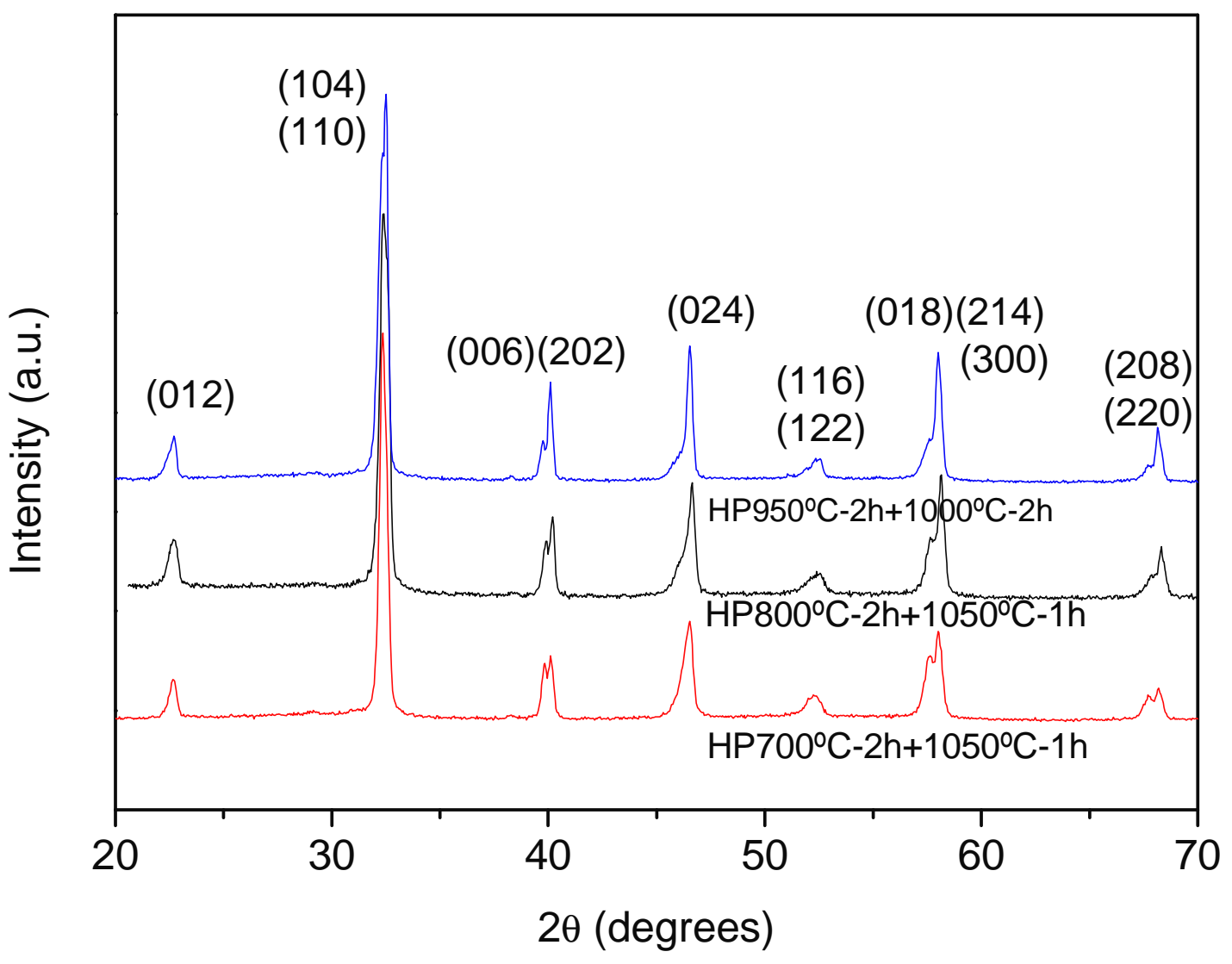

Fig. 1. 

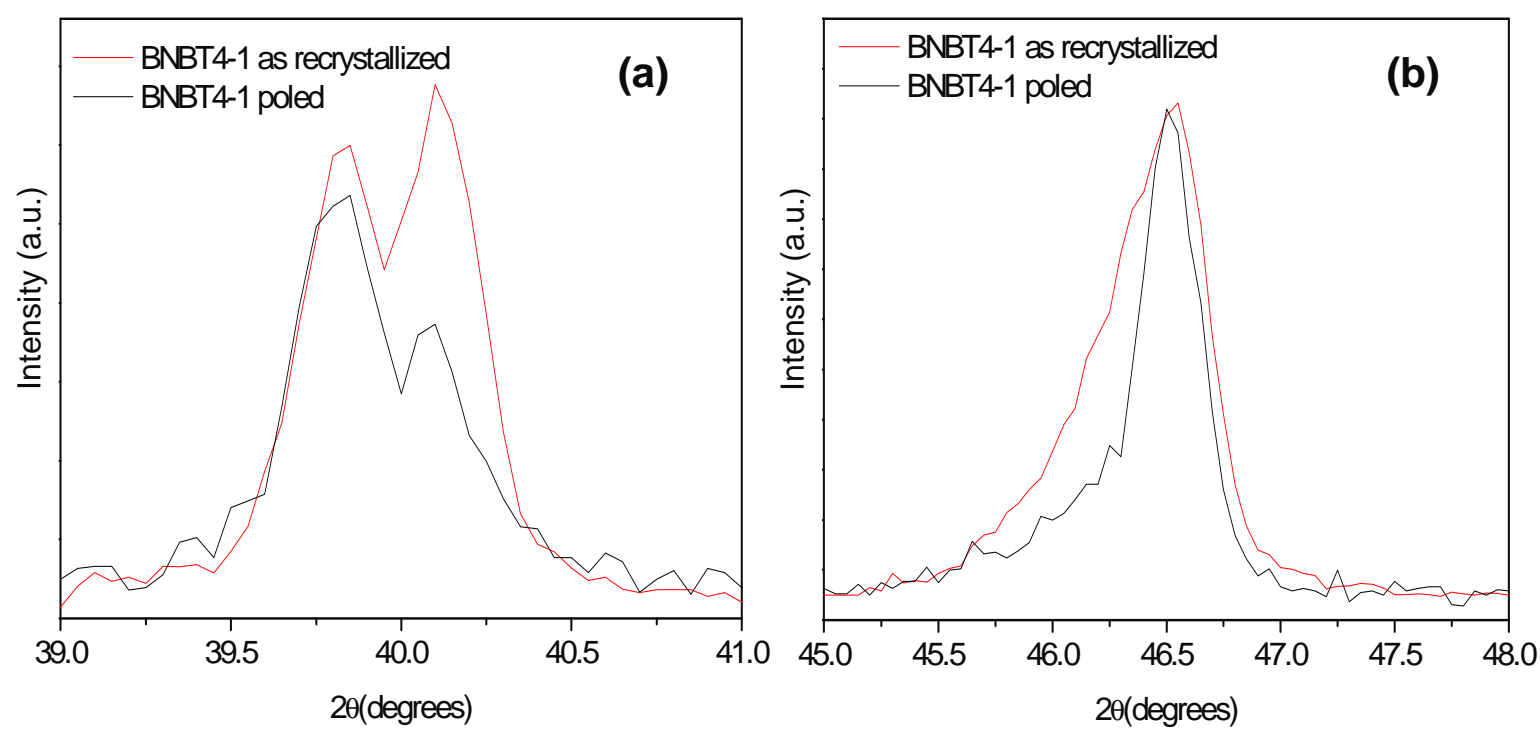

Fig. 2. 

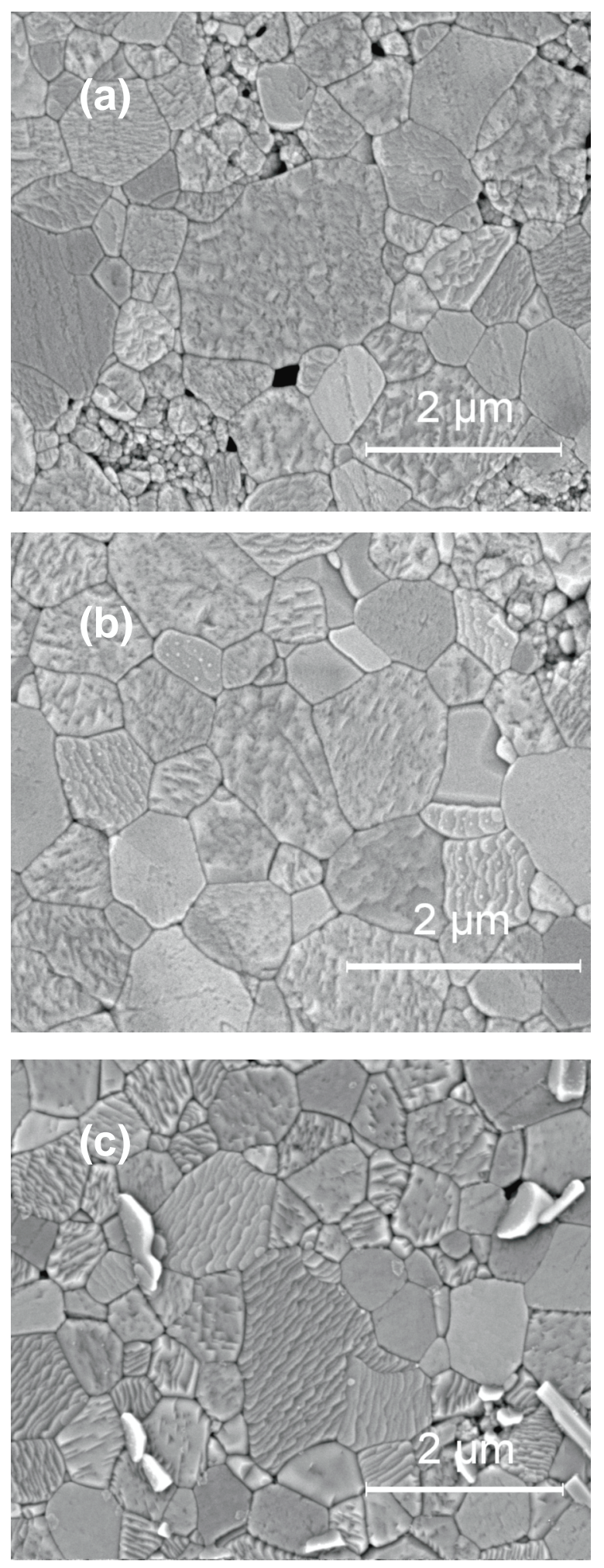

Fig. 3. 

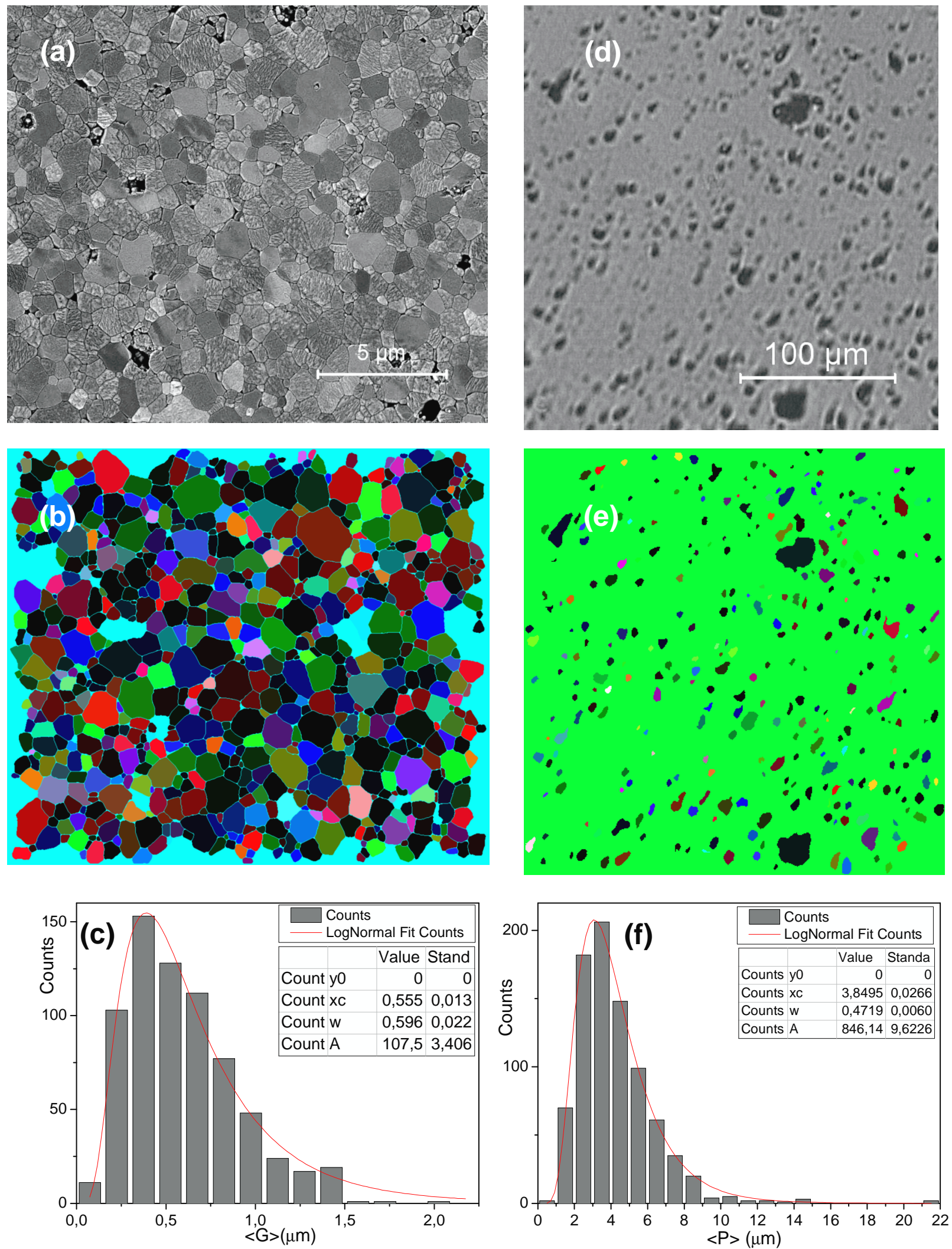

Fig. 4. 

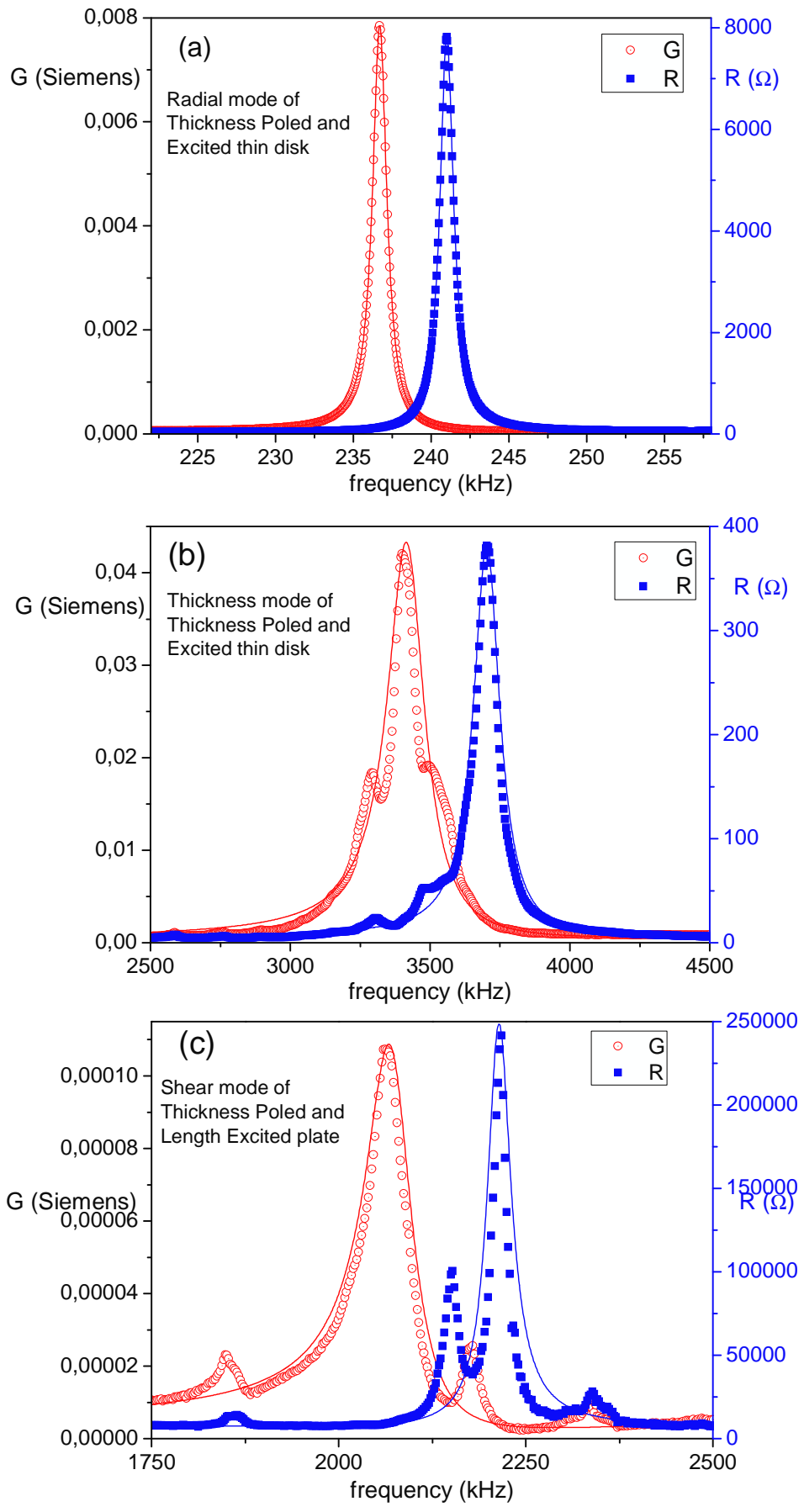

Fig. 5 

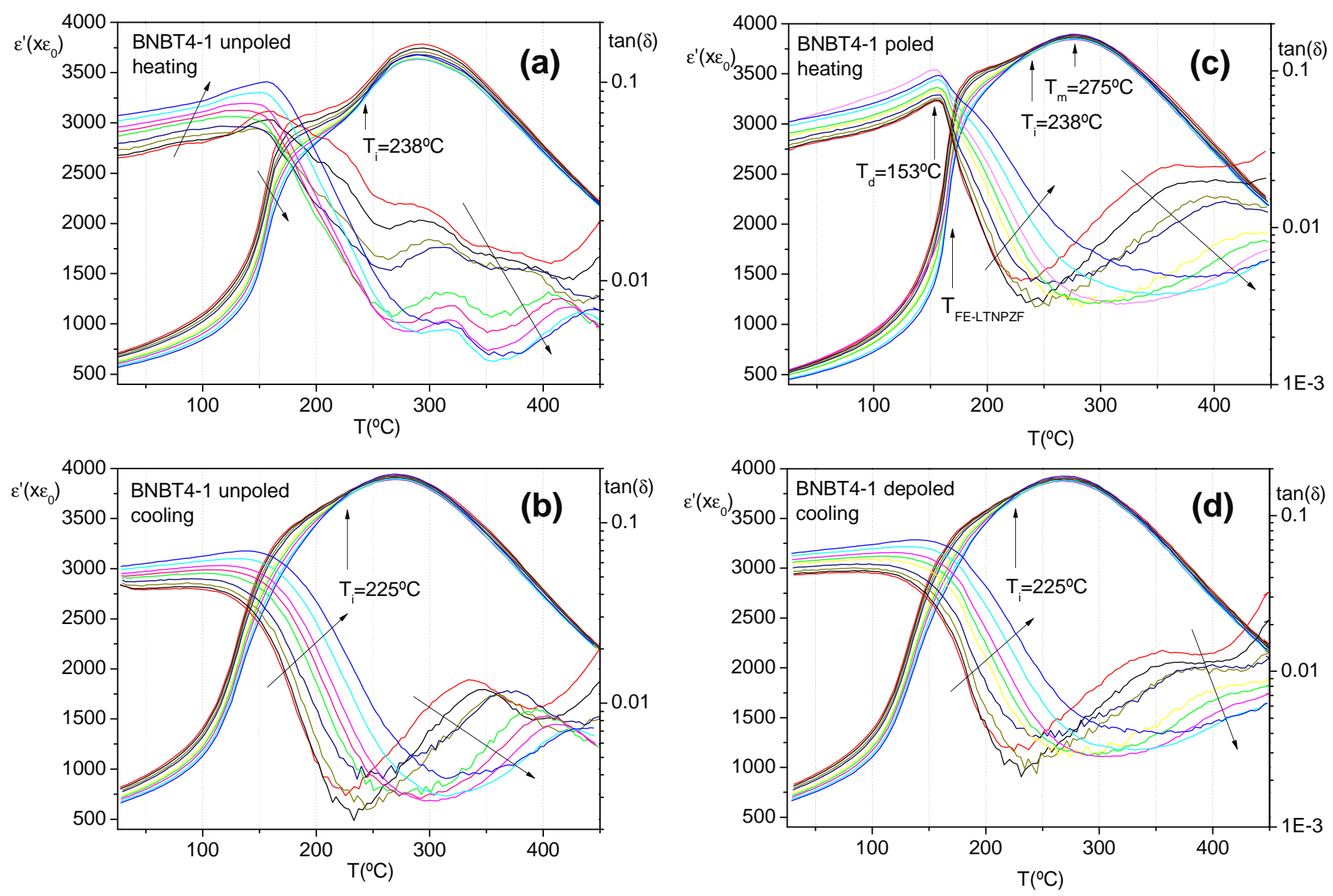

Fig. 6 

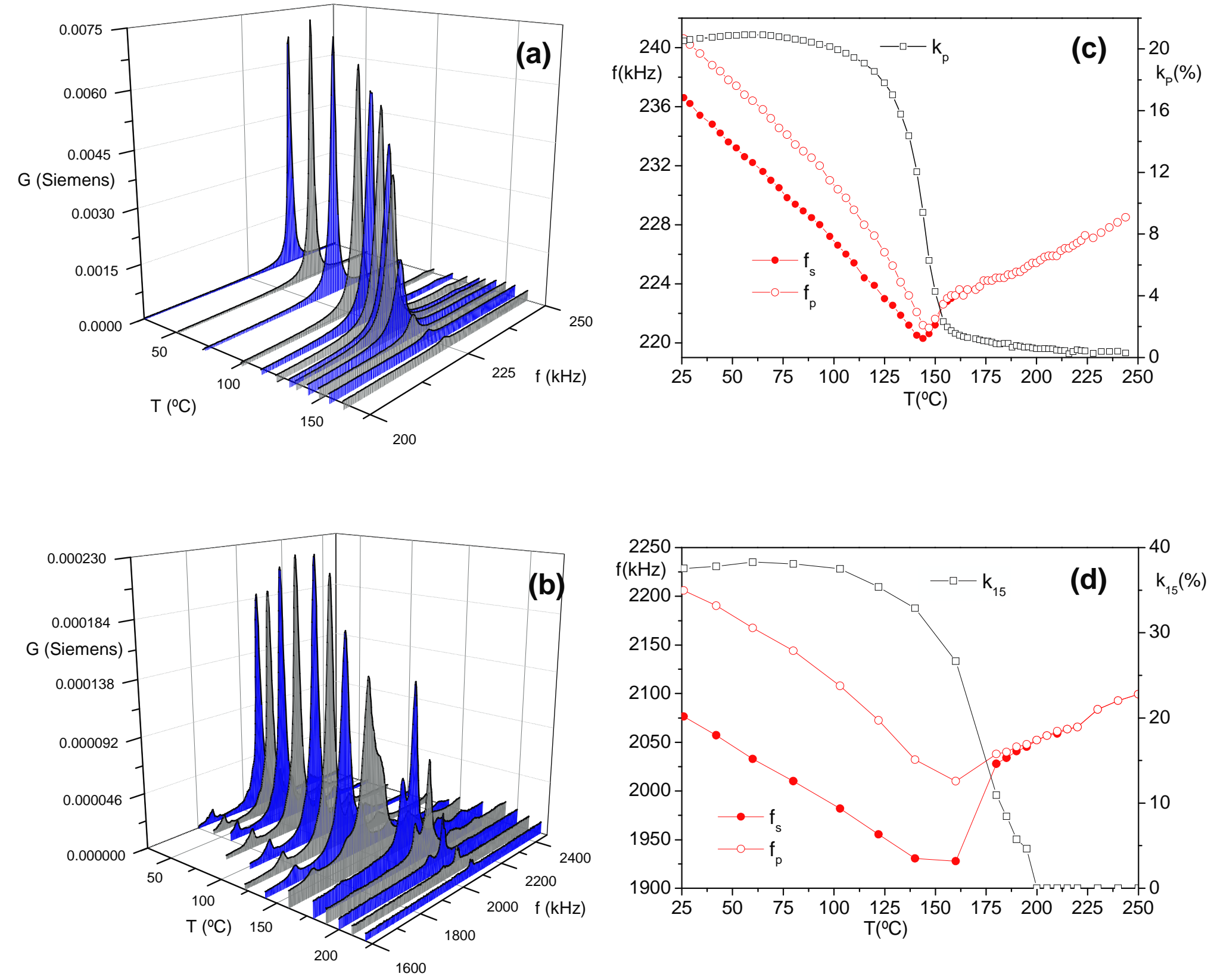

Fig. 7. 